\title{
La dimensión cultural en los paisajes de la Cuarta Colonia de Inmigración de Rio Grande do Sul, Brasil
}

SELECCIÓN VII SEMINARIO INTERNACIONAL DE INVESTIGACIÓN EN URBANISMO

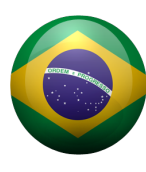

\section{João Paulo Schwerz}

Arquiteto e Urbanista, doutorando do Programa de Pós-graduação em Planejamento Urbano da UFRGS, Professor do Dep. Arq. e Urb. da Universidade Federal de Santa Catarina, Professor do Dep. Arq. e Urb. da Universidade Estadual de Santa Catarina. Florianópolis [SC] Brasil. <jpschwerz@gmail.com>.

\section{Resumen}

El artículo presenta el trayecto y resultados preliminares de la tesis titulada "Patrimonio y Planificación Aproximación a partir del paisaje de Agudo-RS" en elaboración en el Programa de Posgrado en Planificación Urbana y Regional de la Universidade Federal do Rio Grande do Sul - Brasil. La investigación parte de la región conocida como Cuarta Colonia y trata de la relación entre patrimonio y paisaje para desarrollar una lectura amplia del territorio integrando factores culturales que no siempre son considerados, con el objetivo de discutir alternativas para su inserción de forma más eficaz en la planificación territorial del sur de Brasil. Por tanto se busca identificar y evaluar sus paisajes a partir de tres ejes de análisis: (1) experiencia y percepción local; (2) cuadro institucional del territorio; y (3) estructura histórica y estética de los paisajes.

\section{Palabras clave}

Brasil, paisaje, patrimonio cultural, planificación regional.

\section{The Cultural Dimension in the Landscapes of the Immigration Fourth Colony in Rio Grande do Sul, Brazil}

\begin{abstract}
The paper presents the partial results of the thesis "Heritage and Planning - One approach from Agudo's Landscape" in process at the Postgradutate Program in Urban and Regional Planning of the Universidade Federal do Rio Grande do Sul - Brasil. The investigation starts from a region known as Fourth Colony to discuss the relationship between landscape and heritage, so as to read the territory in a broad perspective, integrating cultural aspects not always considered, aiming alternatives for the inclusion of these factors in the territorial planning of Southern Brazil. Therefore, the research identifies and evaluates landscapes from three areas of analysis: (1) local experience and perception; (2) territorial institutional framework; and (3) historic and aesthetic structure of the landscapes.
\end{abstract}

\section{Keywords}

Brazil, landscape, cultural heritage, regional planning. 


\section{Presentación}

La investigación que se presenta a continuación trata de la relación entre patrimonio y paisaje, y de alternativas para su inserción en la planificación territorial del sur de Brasil, partiendo de un estudio de caso que analiza tres diferentes ejes complementarios de información sobre el territorio y la gente local. Primeramente cuenta con una parte basada en encuestas y entrevistas para delimitar la percepción y experiencia del contexto paisajístico, seguido de un panorama institucional que regla las intervenciones sobre el territorio y finalmente busca datos en la estructura histórica y estética de los paisajes en observación. Se busca notar las diferentes miradas y consecuentemente los diversos usos y valores que contiene el territorio para un acercamiento más apropiado desde la perspectiva de la arquitectura y de la planificación en sus varias escalas.

\section{Introducción y Antecedentes}

El interés por el tema, así como la investigación en curso fue motivada por un trabajo realizado entre 2007 y 2009, a partir de una petición del Consórcio para o Desenvolvimento Sustentável da Quarta Colônia (CONDESUS), el cual es un conjunto de nueve municipios de la región central del Rio Grande do Sul - Brasil. Buscaba orientación de la Universidade Federal de Santa Maria (UFSM) para la elaboración de un Plan de Desarrollo Regional ${ }^{1}$.

Durante la etapa de diagnóstico de la región, se realizaron encuestas ${ }^{2}$ a los ciudadanos de las áreas urbanas y rurales de los municipios involucrados, con el principal objetivo de trazar el perfil socioeconómico de la población, pero contando con preguntas orientadas también a los objetivos específicos de los diferentes campos disciplinares del plan. En ese contexto, el equipo responsable de explorar la temática del patrimonio cultural de la región propuso cuestiones para evaluar la representatividad de elementos tradicionalmente señalados como 'patrimonio', como también para desvelar otros aún no incluidos en esa categoría de forma explícita.

De hecho, a partir de las encuestas y otros seguimientos del plan $^{3}$ el paisaje ha emergido con tal potencia que acabó por impulsar estudios más profundos en aquel momento e incluso después de finalizar el proyecto.

Las aparentes contradicciones entre el patrimonio tradicionalmente reconocido y la importancia que el paisaje asume en el contexto local incitan un estudio específico ${ }^{4}$ de maestría, donde se ha profundizado en algunas problemáticas relacionadas a la tesis en curso, y donde aparecen nuevas cuestiones. Así, la disertación referenciada se centró en Agudo, uno de los municipios del Consorcio, y se hicieron nuevas entrevistas - de forma abierta - en menor número pero con más detalles, dirigidas a ciudadanos de diferentes áreas del municipio, de distintas clases sociales, géneros y grados de escolaridad, para llegar a posiciones de entendimiento acerca del patrimonio cultural. Otra vez el protagonismo que asumió el paisaje, aunque no fuera la parte central del trabajo, permitió visualizar su función activa como patrimonio, y es la justificación esencial para el desarrollo de la tesis en curso. Las conclusiones, obtenidas posteriormente en diferentes producciones académicas ${ }^{5}$, y las cuestiones que el tratamiento práctico del tema demanda, conforman la muestra y los medios de la investigación de la cual deriva el presente artículo.

\footnotetext{
${ }^{1}$ Bevilacqua et. al. (2009). Plano Ambiental da Quarta Colônia. Santa Maria, RS: UFSM.

${ }^{2}$ El método utilizado se encuentra detallado en los materiales del Plan de Desarrollo Regional. ${ }^{3}$ Además de las encuestas, los datos y resultados se basan en informes y documentos resultantes de un gran número
de asambleas ciudadanas realizadas en diferentes etapas de elaboración del plan, algunas de las cuales el autor
oportunamente ha participado.
}

${ }^{4}$ Schwerz, J. P. (2009). Valores e conflitos na preservação do patrimônio cultural: o olhar técnico e o olhar comum na identificação do patrimônio arquitetônico de Agudo - RS. Dissertação de Mestrado, Universidade Federal de Santa Catarina, Florianópolis, SC, Brasil.

${ }^{5}$ Schwerz, J. P. (2011). Aprehensión del paisaje como patrimonio a partir de la mirada común. Anales de la Convención de Ordenamiento Territorial y Urbanismo - Cultura, Territorio y Ciudad. Habana, Cuba, 14. 
La tesis en curso tiene como delimitación empírica el municipio de Agudo, en la región central del Estado Rio Grande do Sul. La elección de la zona se debe, además de las posibilidades ofrecidas por los trabajos mencionados, a la formación histórica peculiar de la región, poblada a partir de mediados del siglo XIX por oleadas sucesivas de inmigrantes de origen europeo -Agudo destaca por la inmigración de distintas partes de Alemania- los cuales conformaron, en un espacio geográfico naturalmente diverso, un territorio con características sociales, productivas y constructivas que configuran paisajes particulares que demandan atención, teniendo en cuenta las transformaciones que vienen sufriendo.

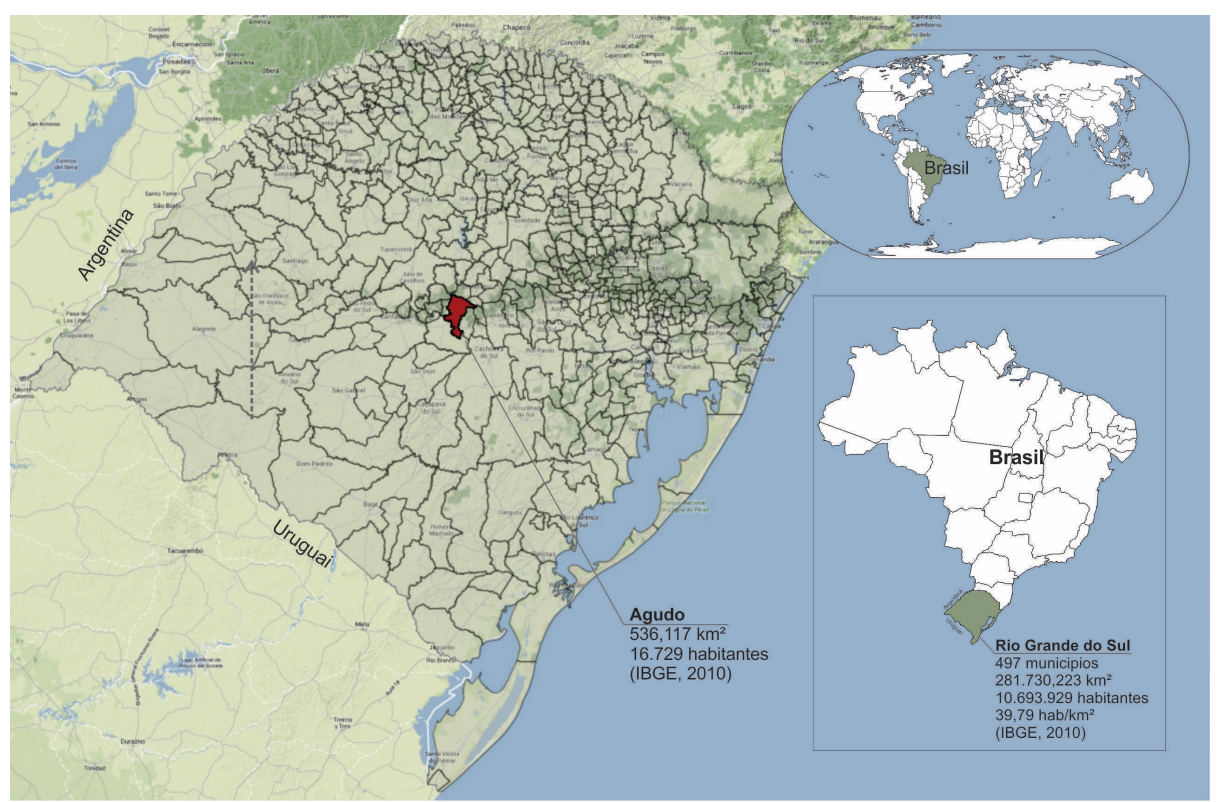

Figura 1. Localización del Estado Rio Grande do Sul y de Agudo [RS]. Elaboración propia.

Agudo está ubicado en la región central del Rio Grande do Sul, extremo sur de Brasil y situado entre los Campos de la Depresión Periférica Gaucha y los Campos del Planalto Medio, Cuenca del Rio Jacuí. Posee una población de cerca de 18.000 habitantes, donde un $60 \%$ aún vive en la zona rural. El punto más alto de Agudo tiene $600 \mathrm{~m}$ por encima del nivel del mar y el más bajo, $50 \mathrm{~m}$ por encima del nivel del mar. Está ubicado en una región incluida como Área Prioritaria de Reserva de la Biosfera de la Mata Atlántica, preservando sustanciales fragmentos de Floresta Estacional Decidua con importante diversidad ecológica. El área posee también sitios arqueológicos y paleontológicos de grande relevancia científica.

A partir del estudio de caso, se desarrolló una lectura del espacio desde el paisaje, asumido en esa tesis como un concepto que trata de forma indisociable cultura y naturaleza, por eso capaz de explorar aspectos culturales no considerados comúnmente en la interpretación, y por consecuencia en la planificación, del territorio en el contexto sur-brasileño.

Por tanto, la investigación se centra en interpretar los paisajes del municipio y distinguir valores a partir de tres ejes de análisis basados: en la experiencia de quienes viven en el lugar, en la estructura reconocida jurídicamente e institucionalmente para el tratamiento del paisaje, y en la dimensión histórica y estética que conforman tales paisajes.

Se espera de esa forma alcanzar el objetivo principal de la investigación, anticipado en este artículo, que trata de destacar determinados aspectos culturales de la formación del territorio que puedan ser integrados a los procesos de planificación urbana y regional en curso, y que sirva de impulso para trabajos e investigaciones con preocupaciones semejantes, o por lo menos que profundice el debate sobre los límites y alcances de la asimilación del paisaje en la planificación en contexto brasileño.

\section{Referencial Teórico}

La comprensión contemporánea de paisaje aporta avances a la interpretación del territorio incluyendo aspectos que, tradicionalmente en Brasil, no son considerados sistemáticamente en su análisis y planificación 
Berque (1994) evidencia el hecho de que el paisaje tiene un largo camino hasta formarse como lo entendemos hoy, y comprueba que se ha manifestado de modos diferentes en las distintas civilizaciones en el transcurso de la historia, enfatizando, de ese modo, que el paisaje se da por mediación cultural. Roger $(2009$, p.23) defiende que ese aporte cultural se manifiesta de dos modos: "in situ", o a través de acciones físicas en el espacio mismo, e "in visu", o de manera representacional, simbólica e imaginaria.

El paisaje es, así, un concepto integrador (Pisón, 2007, p.329) que comporta una instancia concreta comprendiendo configuraciones del espacio geográfico, pero que también conlleva una instancia subjetiva dónde interactúan funciones culturales, sentimentales y simbólicas. Así, ambas instancias son igualmente importantes para la concepción del espacio, ya que interactúan activamente en su construcción y percepción. De la misma manera y por las mismas razones, el paisaje es también indisociable de su sentido temporal, pues es mutable por la interacción activa y creativa entre las instancias citadas. Se fundamenta, por lo tanto, en una base territorial donde asumen protagonismo componentes naturales e históricos que establecen una estructura formal, pero que adquiere interpretaciones y sentidos variados (Mata, 2006).

Siendo mediada por la mirada, la interpretación no puede ser gratuita, conforme advierte Nogué (2009, p.12): las miradas y el paisaje mismo reflejan una determinada forma de organizar y experimentar el mundo. Ese hecho conforma un acercamiento respecto al territorio que contribuye para normalizar las relaciones sociales a partir de la incorporación de símbolos e imágenes que forman patrones de significación y que son capaces de establecer identidad territorial.

Nogué (2009, pp.19-20) defiende que el paisaje es un producto social y como tal debe ser estudiado:

Nada mejor que el paisaje para aplicar una ontología del visible, porque es, a la vez, una realidad física y la representación que culturalmente hacemos de él; la fisionomía externa y visible de determinada porción de la superficie terrestre y la percepción individual y social que genera; un tangible geográfico y su interpretación intangible. Es, a su vez, significante y significado [...].

El paisaje como expresión geográfica resulta de la relación de tres niveles de configuración: morfología, percepción y representación (Pisón, 2007, pp.329-330). Berque (1995) explica los diferentes métodos de análisis del paisaje que pueden ser descriptivos, sistémicos o perceptivos. En su dimensión inmediatamente visible, los componentes estructurales, formales y funcionales establecen un primer acercamiento al entendimiento de los paisajes (Pisón, 2007, pp.329-330). Pero el mismo autor advierte: "además del conocimiento formal está la vivencia del paisaje en un nivel personal, a lo que solamente se llega por la experiencia directa, ya que el paisaje es realidad sensible, no solamente materia" (p.333).

Sabaté (2008, p.252) explica la trayectoria de los estudios sobre paisaje y su intrínseca relación con la cultura, que han apoyado el reconocimiento del concepto "a partir de una creciente preocupación con el patrimonio" y han desempeñado un importante rol en la planificación y gestión territorial actuales.

El sentimiento de pérdida ante las rápidas transformaciones de los paisajes, sea en su función identitaria personal como de sus valores colectivos hace necesario su debido entendimiento por medio de métodos que comprendan la debida interrelación entre los valores del paisaje como patrimonio, como portador de calidad ambiental y como recurso económico para convertirse en un factor más en la ordenación del territorio (Sabaté \& Gonzáles, 2009).

Según Mata (2006, p.212) metodologías territoriales del paisaje deben buscar una lectura que abarque la diversidad de configuraciones del territorio para tutela de sus valores y gestión de sus cambios más allá de énfasis geográficas, ecológicas o perceptivas. Para eso se basan en tres fases fundamentales que son: identificación y caracterización del paisaje, evaluación del paisaje y objetivos de calidad paisajística. 
Para lograr los objetivos de la tesis, la investigación hace foco en la identificación y caracterización del paisaje, buscando evidenciar los valores presentes en los paisajes de Agudo a partir de una serie de análisis que incluyen escalas temporales y espaciales distintas. Por medio de una propuesta complementaria de método, pero notoriamente epistemológica, se suman experiencias vivenciales que ponen de relieve lo autóctono de los paisajes estudiados (Jackson, 2010), considerando que los mismos están dentro de un contexto formalizado en nivel ejecutivo de gestión ambiental que no consideran su nivel estético, aunque no puedan existir sin él, como argumenta D’Angelo (2001). Así se busca una más adecuada ecuación entre las dimensiones - económica, ambiental y estética - en los procesos de ordenación y gestión del territorio, justamente la relación con la que esta investigación se compromete.

\section{Referencial Metodológico}

A partir de las cuestiones comentadas anteriormente y de los supuestos teóricos presentados, se da inicio a una exploración desarrollada esencialmente en tres ejes de análisis, que constituyen el procedimiento propuesto para el alcance de los objetivos planteados: I. análisis de lo que estructura los paisajes para sus habitantes, a partir de las respuestas obtenidas en campo; II. Análisis de lo que estructura los paisajes institucionalmente, o sea, el conjunto de procedimientos y leyes en curso para tratamiento de los paisajes desde donde se definen sus condicionantes de actuación y gestión; y III. Análisis de lo que estructura los paisajes histórica y estéticamente, a partir de documentos y producciones artísticas sobre los paisajes en evidencia.

El primer de los ejes se refiere al factor experiencial que colectivamente va a atribuir sentimientos de identidad a los paisajes. Como ya se ha comentado anteriormente, ese factor se hace importante a partir de trabajos anteriores en el área de estudio y es justamente lo que incita y justifica la investigación en curso. Se produce entonces un panorama de lo que es perceptible y compartido acerca del paisaje, a partir de quienes, en última instancia, lo experimentan más profundamente. Utilizando los mismos recursos se encuentran también pistas de las aspiraciones que la gente tiene respecto a su territorio, y que posiblemente tendrán reflejos en los paisajes futuros. Para constituir esa perspectiva se compilan palabras clave que fueron recurrentes en las encuestas y entrevistas realizadas, que son en seguida esquemáticamente cartografiadas para conformar un primer "mapa de valores", que será confrontado, a la secuencia, con otras camadas de informaciones derivadas de los otros ejes observados.

En segundo lugar, sumado por factores institucionales contundentes, se adjunta un análisis centrado en los elementos físicos, geográficos y biológicos que estructuran y condicionan el territorio de Agudo. Para eso, se parte del juicioso trabajo de la Fundação Estadual de Proteção Ambiental (FEPAM) que elabora y propone una división del Estado (Rio Grande do Sul - Brasil) en Unidades de Paisagem Natural o UPNs. Esas unidades funcionan como una primera zonificación. Las unidades son utilizadas como base para licencias de nuevas reforestaciones exóticas, pero también aspiran incluir otras actividades productivas y proyectos de gran impacto ambiental. El trabajo citado cuenta con una delimitación fundada en los aspectos sobre todo físico-geográficos, pero incluye índices ecológicos de flora y fauna e incluso apunta sitios de importancia paleontológica, entre otras informaciones debidamente referenciadas por medio de GIS. Además de ser una base científica determinante para este estudio, presenta condicionantes legales para tomar decisiones. Sirve además de base de confrontación entre los criterios utilizados para delimitar las UPNs y los criterios alternativos que esta investigación busca añadir para un nuevo nivel de lectura del paisaje.

Además de dicho documento y del reciente Plan de Desarrollo Regional al que también se hace referencia, también se han investigado otros trabajos técnicos y científicos de diversas disciplinas, que conforman el panorama de actuación técnica y jurídico-institucional que pauta esta investigación (ver referencias bibliográficas).

Por fin, el tercer eje de análisis está comprometido en buscar relaciones intrínsecas entre el territorio y su paisaje como patrimonio, que sean perceptibles pero no evidentes, y que puedan condicionar la preservación o no preservación de valores. Por ello se hacen lecturas que buscan entender cómo esos paisajes se conformaron históricamente y cómo son revelados estéticamente. 
Es una doble cuestión que trata de poner en un mismo plan la ocupación, usos y evolución del territorio bien como las representaciones que desde esa óptica estructuran y ponen de manifiesto características singulares y otros valores de los paisajes. En esa fase fueron compendiados mapas históricos que comprueban las primeras divisiones de los lotes rurales y urbanos así como relatos históricos, diferentes expresiones artísticas (de pinturas históricas, pasando por literatura, fotografía y hasta dibujos escolares) de diferentes épocas respecto a las diferentes apropiaciones (prácticas o simbólicas) que transforman el territorio y las formas resultantes heredadas que conforman sus paisajes. También tienen un papel preponderante los patrones de ocupación y la distribución histórica de actividades productivas, y las redes de infraestructuras construidas a lo largo del tiempo. En ese contexto, la red de caminos se destaca por ser desde donde se mira, se conoce y se reconoce el paisaje, y por lo tanto toma cierta proporción, demandando en ese eje de análisis un estudio de las visibilidades por medio tanto de modelos tridimensionales como de fotografías, acompañado también de dibujos y esquemas explicativos de los principales modelos de ocupación y uso en el territorio considerado.

\section{Resultados Preliminares}

Lo que se presenta a continuación son resultados iniciales a partir del material reunido y de los análisis desarrollados hasta el momento sobre el municipio de Agudo cuyo nombre pertinentemente hace referencia a un monte solitario de perfil afilado - agudo - que marca el paisaje.

\subsection{El Paisaje en el contexto local}

Para la elaboración del Plan de Desarrollo Regional se consideraron encuestas a los habitantes de los municipios, las cuales se adjuntan abajo. Las preguntas de carácter abierto y cerrado fueron distribuidas en las zonas rurales y en las zonas urbanizadas de todos los municipios del Consorcio de forma proporcional al número de viviendas (datos del CENSO 2000 del Instituto Brasileño de Geografía y Estadística - IBGE) logrando aproximadamente la participación de un $2 \%$ de toda la población involucrada. Esos datos representan el peso más significativo en los análisis aquí presentados, por su amplitud tanto numérica como espacial. Pero además de ello, los datos y resultados se basan en la participación directa, informes y documentos resultantes de un gran número de asambleas ciudadanas en diferentes fases de elaboración y aplicación de dicho Plan. Por fin, fueron realizadas entrevistas directas en menor número, pero con mayor profundidad a actores seleccionados del territorio en un estudio específico ${ }^{6}$, que también conforma la muestra de ese primer eje propuesto.

El objetivo principal de las preguntas era conocer el nivel de representatividad y asociación identitaria de la población con los diversos municipios que componen la preconcebida "región Cuarta Colonia" y con aspectos tradicionalmente "patrimonializados". Por otro lado había una búsqueda por nuevas formas de identificación de la gente con el territorio.

Lo que se percibió inicialmente fue una persistencia de aspectos ya difundidos como la "culinaria" y las "fiestas" que tienen un reconocimiento incluso desde fuera de la región. Ambas mantienen una fuerte conexión entre sí y entre otro factor importante en la región que es la religiosidad - en el caso de Agudo principalmente de confesión luterana - ya que la comunidad se organiza en torno a la iglesia, incluso en la zona urbana, para celebrar dichas fiestas. Son aspectos importantes que manifiestan una fuerte cohesión social relacionada a la producción agrícola y sus desdoblamientos más típicos: la cuca - especie de pan recubierto con diferentes tipos de dulces, generalmente frutas -, embutidos tipo longaniza, y fresas, con una gran fiesta dedicada a su cosecha.

Otro fuerte aspecto ya conocido, y reforzado en las encuestas, fue la fuerte polarización entre las dos principales etnias que colonizaron la región: italianos y, esencialmente en el caso de Agudo, alemanes. El "contraste" suele ser bien ostentado en ambos lados y realmente es apreciable, aunque haya naturalmente muchas cosas en común, e incluso con contribuciones de otras etnias de origen europeo, indígena y africano. El carácter de "región de inmigración" es un fuerte elemento identitário y es reconocida en un ámbito provincial.

\footnotetext{
${ }^{6}$ Método y resultados se pueden ver en: Schwerz (2009). Op. cit., Dissertação de Mestrado, UFSC, Florianópolis, 2009.
} 
Por otro lado fue sorprendente la fuerte representatividad que la palabra "paisaje" asume en las encuestas y también en las entrevistas, lo que permite visualizarlo activamente como patrimonio ${ }^{7}$. En el contexto de las encuestas "paisaje" no era más que una provocación, estratégicamente dejada como pregunta final. Cabe destacar que paisaje no es un argumento presente de forma declarada en los debates, y fue apenas tocado de forma puntual en las asambleas. Lo que sí aparece desde ahí son los conflictos agua x polución, uso del agua, deforestación x producción, etc. Algunos embates notoriamente relacionados son asumidos a partir de una preocupación ecológica reciente, pero muchas veces de forma reactiva. La discusión es esencialmente desde un punto de vista económico de uso de la propiedad ya que las decisiones políticas tomadas en escalas superiores interfieren directamente en la realidad de esas comunidades como en el caso del Plan en cuestión. A lo que se quiere hacer referencia, con ese caso, es que difícilmente los argumentos relacionados con el paisaje abarcan aspectos de fondo histórico y/o estéticos, o sea, no alcanzan directamente la cuestión del paisaje como apreciación o disfrute.

Aún así es muy significativo que el paisaje haya sido el "elemento tangible" más representativo en todos los municipios tanto en zonas urbanas como rurales constando entre el 12 y $20 \%$ de los totales municipales y acercándose a un $15 \%$ en toda la región investigada. Se puede interpretar que la idea de paisaje es muy asociada a la indiscutible presencia "natural" del entorno: montañas, montes, extensas llanuras, ríos y arroyos, vigorosa vegetación, etc., pero también se asocia a los cultivos tradicionales del tabaco y del arroz; y se manifiesta en escalas mucho más pequeñas, como los huertos particulares y flores en los espacios públicos. Otros aspectos subrayados tienen que ver con el sentimiento de amor y de conexión íntima con la tierra como fuente de trabajo pesado, pero también de sustento y de orgullo. De la misma forma eso tiene que ver con un modo aún familiar de trabajo, principalmente en las pequeñas propiedades - característica de esos lugares - que denota relaciones sociales tradicionales que se van perdiendo en los días de hoy.

Entre las respuestas se percibe que los paisajes están vinculados a la amplitud visual que el relieve propicia, a pesar de que también son citados los "fondos verdes" de las montañas de alrededor. El paisaje perceptible se hace importante en las preguntas sobre cómo deberían ser las ciudades en el futuro, en que aparecen consideraciones sobre mirar el horizonte "sin edificaciones altas". Aquí también se resalta el mantenimiento y la importancia del silencio y de la tranquilidad.

En Agudo, además del monte que nombra la ciudad, hay muchos otros onomásticos geográficos o paisajísticos incorporados al vocabulario de la gente como en todos los municipios estudiados. También las vías o caminos originales, las Linhas, Travessas y Picadas, siempre continuadas por un nombre que, en general, hace referencia a puntos de procedencia como Linha dos Pomeranos, Linha Boêmia, o a accidentes geográficos, como Picada do Rio. Los montes tienen un papel preponderante, pero también las llanuras o várzeas, puntos de producción tradicional del arroz. La otra cultura que se destaca, también muy tradicional, es la de tabaco, pero que se presenta mucho más repartida por el territorio. Los ríos y arroyos tienen en el contexto paisajístico extrema importancia y son constantemente citados con múltiples funciones (de producción de energía hasta balnearios). Además de esa macro estructura son puntuados algunos elementos "naturales" escénicos como cascadas y una gruta, en especial. Luego son nombrados como locales de referencia algunas iglesias y salones de baile aunque no tengan más uso. En general también hay referencias constantes a las propiedades utilizando los nombres de familia. A continuación son compiladas las palabras clave que dan origen a un mapa de elementos destacados por la población y son presentadas fotos de algunos elementos:

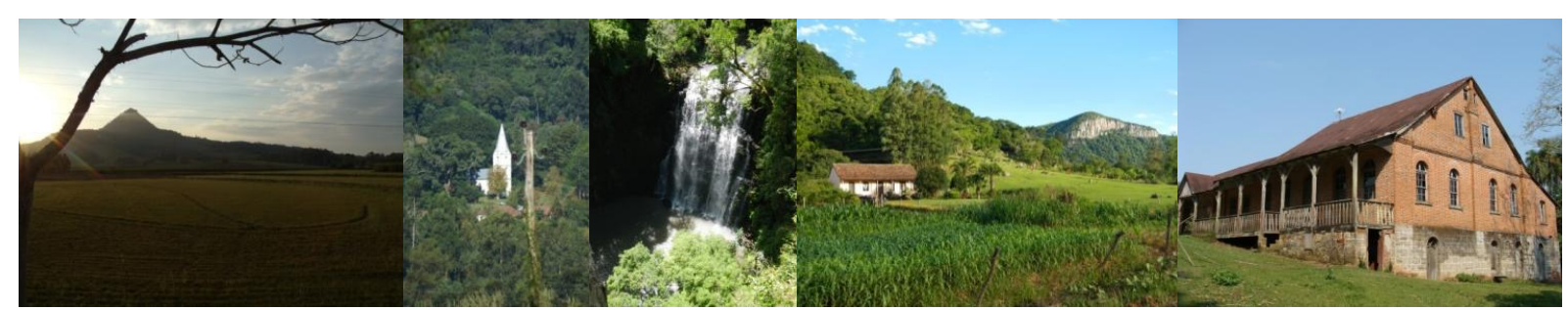

Figura2. Algunos de los elementos del paisaje destacados: El monte "Agudo", Igreja Luterana da Picada do Rio, la cascada Raddatz, monte Cerro da Igreja y el salón de baile Ehrhardt. Fotos del autor, 2008, 2010, 2013.

\footnotetext{
${ }^{7}$ Schwerz (2011). Op. cit., Anales..., Habana, Cuba, 14.
} 


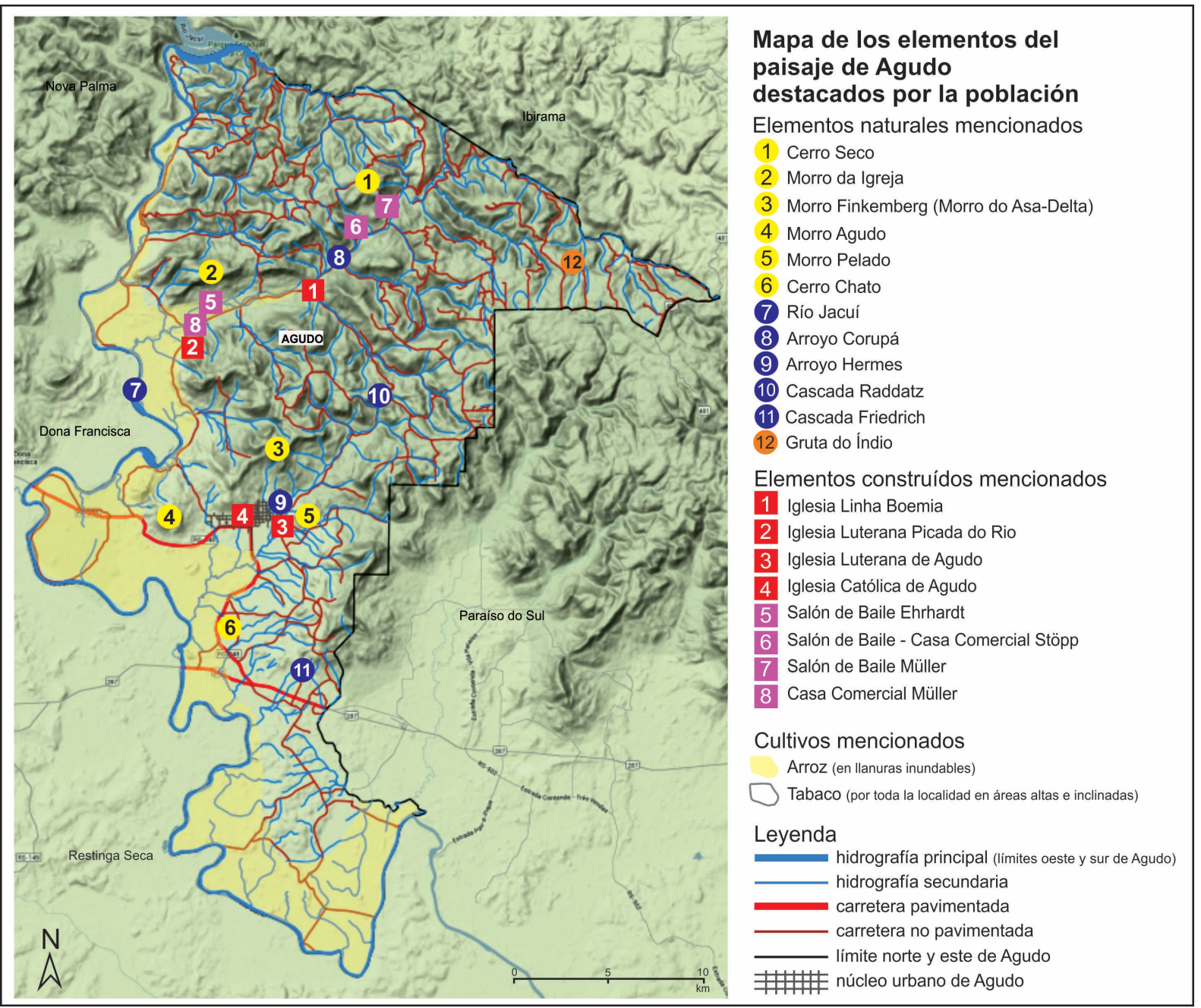

Figura 3. Elementos del paisaje del municipio de Agudo destacados por la población local en entrevistas, encuestas y reuniones del Plan de Desarrollo Ambiental para la Cuarta Colonia. Elaboración propia.

\subsection{El paisaje en el contexto institucional}

En el año de 2005 el Gobierno del Estado Rio Grande do Sul crea por intermedio de sus Secretarías y Fundaciones competentes el Mapeo de las Unidades de Paisaje Natural (UPNS) que va a ser un importante instrumento de gestión ambiental, utilizado a partir de entonces para licenciamiento de silvicultura en ámbito estadual ${ }^{8}$. Lo importante para esta investigación es que el documento viene a complementar el Código Ambiental Estadual (Lei Estadual no 11.520/2000) y se convierte actualmente en la referencia no sólo para reforestaciones, como para todos los proyectos de impacto ambiental considerable.

En sus definiciones sectoriza el territorio del estado en unidades de paisaje con características naturales semejantes para que puedan ser utilizadas como unidades de gestión ambiental. Los criterios reflejan características fisionómicas y paisajísticas, que presentan un alto grado de homogeneidad interna pero que no consideran transformaciones de origen antrópico. Esos supuestos, explicados por sus formuladores, se justifica por una serie de ventajas, como la generación de unidades que tienen límites físicos naturales y no políticos, optimizando datos puntuales (por ejemplo de flora y fauna), a la vez que permiten el dimensionamiento de impactos ambientales en escala regional.

Las UPNs fueron definidas por cruce de bases digitales de geomorfología, vegetación potencial original, suelo y altimetría, en escala 1:250.000. Los mapas obtenidos por los sucesivos cruces fueron sometidos

${ }^{8}$ El trabajo completo, con sus procedimientos metodológicos, objetivos e instituciones involucradas puede ser consultado en la biblioteca digital da FEPAM en: http://www.fepam.rs.gov.br/biblioteca/zoneam silvic.asp 
a recurrentes evaluaciones por expertos en diferentes campos de conocimiento. Por fin fueron definidas 45 UPNs en todo el Estado, con áreas variables entre 20.318,44 e 2.786.977,65 ha. El hecho de la clasificación resultante es neutra respecto al uso antrópico tiene como objetivo que las UPNs sean adoptadas en el futuro como unidades de planificación, gestión y zonificación de otras actividades.

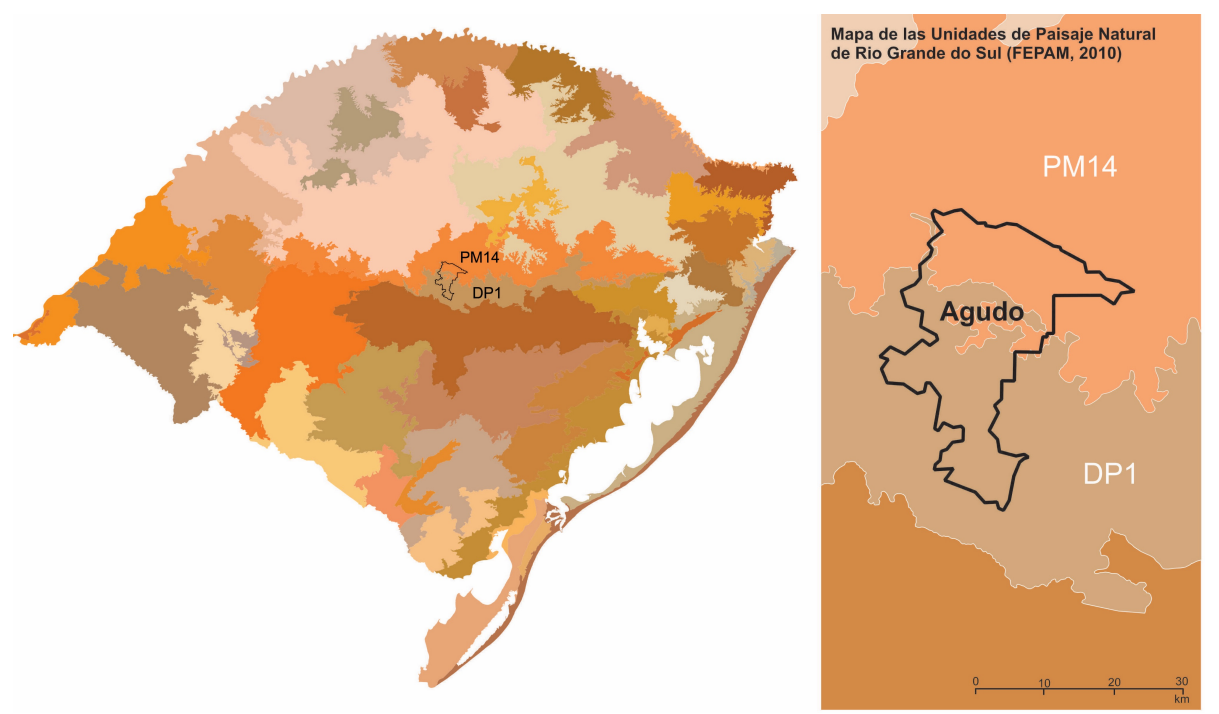

Figura 4. Mapa de las Unidades de Paisagem Natural (UPNS) del Rio Grande do Sul. Elaboración propia a partir del mapa FEPAM (2010). La delimitación es producto del trabajo desarrollado en 2004 por técnicos de la Fundação Estadual de Proteção Ambiental (FEPAM), Fundação Zoobotânica (FZB) y Departamento Estadual de Florestas e Áreas Protegidas por encargo de la Secretaria Estadual de Meio Ambiente do Rio Grande do Sul. A la derecha una ampliación del área en estudio con las dos UPNs que la envuelven.

Las directrices fueron elaboradas por secciones específicas que contemplan áreas protegidas, flora y fauna amenazada, recursos hídricos, sitios paleontológicos, manejo y poblaciones tradicionales y paisaje, en lo que establece, entre otras "conservar el paisaje típico de las unidades, desde donde se debe investigar elementos relevantes por medio de la percepción de las comunidades locales".

A continuación se presenta una descripción de las dos Unidades de Paisaje que conforman el municipio de Agudo [RS, Brasil] según el documento institucional presentado anteriormente, de forma reducida por cuestiones objetivas para este artículo.

\subsubsection{Unidad de Paisaje DP1}

Principales elementos del paisaje: región de planicie ubicada al norte del río Jacuí, en la Depresión Central, extendida desde Santa Maria hasta las proximidades de Porto Alegre (capital). Su vegetación original es Floresta Estacional Decidua de Tierras Bajas y su topografía plana, con altitudes variables de 0 a $100 \mathrm{~m}$, con montes testigos de hasta 400 , correspondiendo al primer nivel de la pendiente abrupta de la sierra.

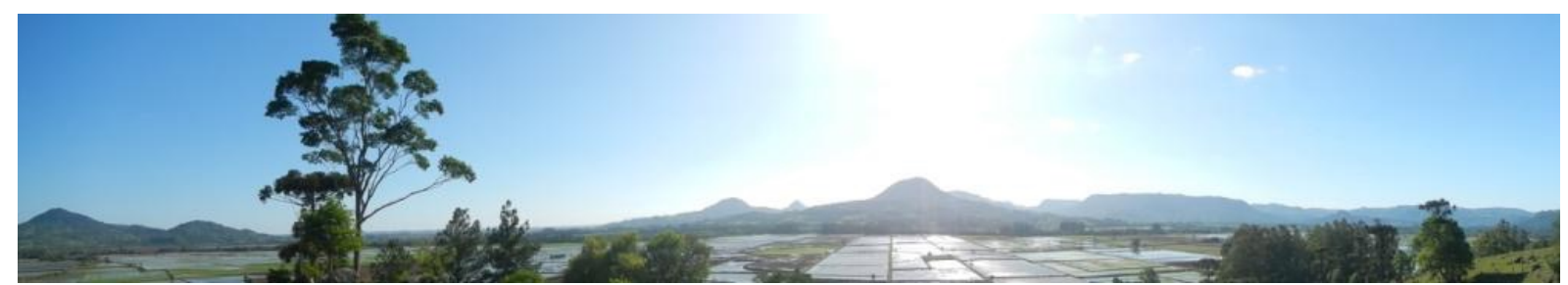

Figura 5. Panorama típico de la UPN DP1 en el municipio de Agudo [RS] Brasil. Foto del autor, 2013.

Aspectos actuales relevantes: región dónde hubo supresión casi total de Floresta Estacional, sustituida por cultivos diversos destacando el arroz en las llanuras (várzeas) de los ríos. En general la región es caracterizada por establecimientos rurales pequeños de productividad mediana, con excepción para la orizicultura que presenta áreas con la más grande productividad del Estado. Hay presencia de dos Unidades de Conservación y gran ocurrencia de sitios paleontológicos agregando valor paisajístico a la 
región. Hay presencia significativa de sitios arqueológicos, registro de 5 especies de fauna amenazada y presencia significativa de áreas quilombolas (comunidades remanentes del período de esclavitud donde hay descendientes viviendo).

Objetivos de conservación: conservación de los remanentes de Floresta Estacional Decidua; Conservación de charcos y áreas húmedas; Protección de las áreas de ocurrencia de sitios paleontológicos y ambientes naturales asociados.

\subsubsection{Unidad de Paisaje PM14}

Principales elementos del paisaje: región del Planalto dos Campos Gerais, caracterizada por la escarpa sur de la Serra Geral, zona de contacto entre el altiplano y la depresión central. Su vegetación característica es la Floresta Estacional Decidua. Presenta altitudes variables entre 50m y $600 \mathrm{~m}$ y topografía accidentada, donde se destacan los valles de los ríos Jacuí y Taquari.

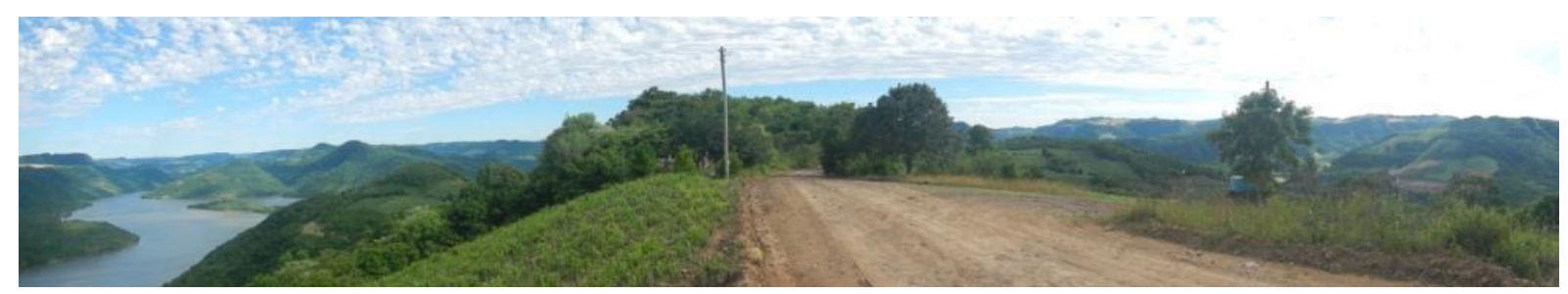

Figura 6. Panorama típico de la UPN PM14 en el municipio de Agudo. Foto del autor, 2013.

Usos actuales relevantes: La escarpa del altiplano donde se ubica toda la unidad presenta un relieve fuertemente ondulado tendiendo al paisaje montañoso, profundamente desgastado por la erosión, con declividad media cerca de los $50 \%$. Constituye una de la regiones representativas de la Floresta Estacional Decidua que recubre las pendientes sur del altiplano, con remanentes significativos de la zona de amortiguación de la Reserva de la Biosfera de la Mata Atlántica. Es una región caracterizada por pequeñas propiedades rurales con actividades diversificadas. Hay presencia de dos Unidades de Conservación y de sitios arqueológicos, de seis especies de fauna y 23 registros de flora amenazada. Hay presencia de áreas quilombolas y tierras indígenas. También contiene sitios paleontológicos. Tiene gran número de registros de atractivos turísticos.

Objetivos de Conservación: conservación del pasillo de mata remanente (Zona Núcleo y de Amortiguamiento de la RBMA), conservación de las áreas de interés paisajístico y cultural, especialmente aquellos relacionados a la colonización italiana.

Desde un análisis en la escala propuesta por el documento, las UPN se muestran útiles desde una mirada general, sobre todo para entender los factores físicos que condicionan el territorio. Con la intención de hacer un puente entre esa escala y otra intermediaria, se recurre a fotos de satélites, desde donde se pueden percibir inmediatamente algunos patrones de ocupación. Destacan en ese nivel el contraste entre el medio natural y los retos a que las colonias de inmigrantes se sometieron en la época de la ocupación. Se presentan a continuación (Figura 7) dos fotos de escala semejante de dos patrones diferentes de ocupación.

En la primera foto (Figura 7) se destaca un patrón de ocupación típico en toda la región. Lo que se quiere registrar en este caso es la división muy marcada de la llanura junto al río. Se nota un contorno estrecho de mata ciliar y luego lotes prácticamente perpendiculares al curso principal de agua (Jacuí), zona típica de cultivo de arroz irrigado, por conformar el nivel más bajo y por sufrir eventuales inundaciones. Secuencialmente en una zona inmediatamente más alta se colocan los caminos, muchas veces Linhas o Picadas (la que aparece en la imagen 1 de la Figura 7, arriba es la Picada do Rio), que son las vías iniciales de exploración del territorio y desde donde eran trazados los lotes. Con el corte abrupto del relieve que se configura en el caso tratado, el trazado sigue con una rigidez relativa y la división de lotes perpendicularmente encuentra los cerros. Esos son bastante vegetados, seguramente con mata nativa (Floresta Estacional Decidua), pero así que el terreno permite empiezan a notarse áreas de inclinación mediana con cultivos diversos, entre ellos el tabaco. 


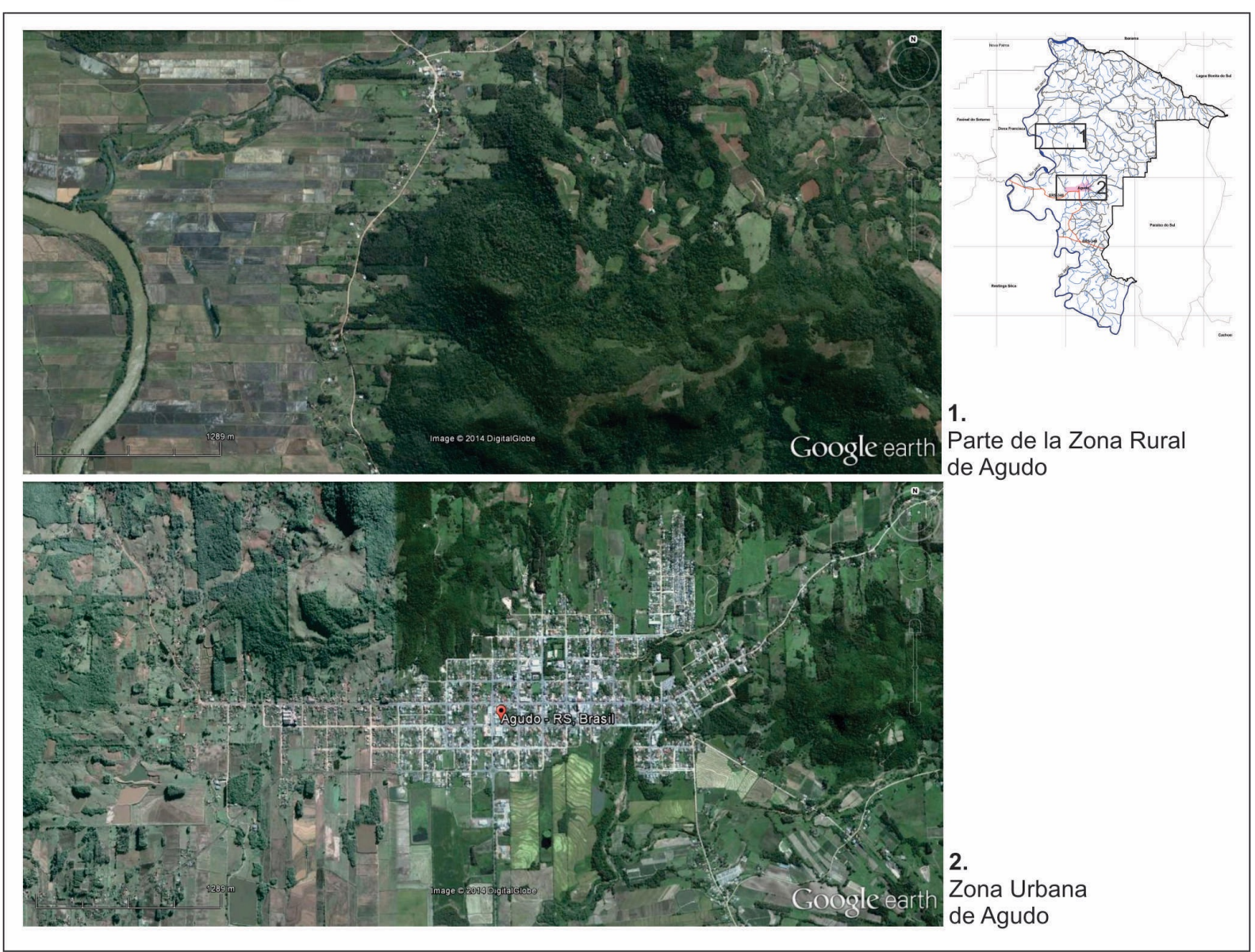

Figura 7. Imágenes de la Zona Urbana y Zona Rural de Agudo donde se puede observar patrones de ocupación ortogonales coloniales iniciales en contraste con el diversificado medio natural. Elaboración a partir de imagen Google Earth (2014) y mapa del Plan de Desarrollo (2009).

La segunda foto (Figura 7) configura el patrón "urbano" de Agudo, semejante a la gran mayoría de los municipios de la región, extremamente ortogonales. La sede de Agudo está proyectada en una línea (Linha Leste do Morro Agudo) entre dos montes que adquieren mucha fuerza como referencia espacial, y también sentimental: El Morro Pelado (algo como Monte Desnudo) y el Morro Agudo (Monte Afilado) que nombra el municipio. Desde ahí parten calles ortogonales hasta que la geografía distribuye los principales caminos. En esa foto, como en la anterior, también se puede observar un patrón de ocupación en línea junto a las vías que son forzosamente lo más ortogonales posibles. Otra marca fundamental - que no es característica solamente de Agudo - es la transición, o mejor, la no transición entre lo urbano y lo rural, lo que hace cuestionar tal división.

\subsection{El paisaje en el contexto histórico estético}

El presente eje de análisis surge para completar los anteriores exhibidos. Por un lado, la mirada amplia de los paisajes entendidos por quienes tienen la competencia de gestionarlos carece de detalles que solamente son perceptibles bajando el punto de vista del que los observa, pero principalmente entendiéndolo como espacio tridimensional, experienciado. Por otro lado, la percepción personal y colectiva no siempre da cuenta de evaluar proporcionalmente valores propios justamente por su relativa trivialidad. El rescate de un debate en términos estéticos no debe ser un demérito para un proceso de planificación que pretende ser profundo y abierto y que debería ser capaz de reconocer valores además de los económicos y ambientales.

En la búsqueda de conexiones, veladas hasta ahora, que permitan entender las diferentes formas de patrimonio que constituyen el paisaje fueron activadas aquellas que por primera vez transforman de modo definitivo el territorio. Eso empieza a partir de mediados del siglo XIX con un esfuerzo de colonizar una región prácticamente salvaje con gente de lejanos parajes. En el caso específico de 
Agudo, hay marcadas influencias germánicas que persisten desde su fundación. Aunque superado el aislamiento geográfico que caracterizaba las colonias del sur de Brasil, después de 4 generaciones, la mayoría de su población desciende de aquella etnia y sostiene idioma y dialectos originales. Mantiene, además, un $70 \%$ de su población viviendo en la zona rural, en pequeñas propiedades que subsisten con diversificación de productos cultivados con mano de obra familiar como la organización inicial propugnaba, o sea, las primeras iniciativas en Brasil de ocupación de un territorio que no fuera por latifundios de una única cultura basada en mano de obra esclava. Sumado a todo eso, el municipio sigue con cultivos tradicionales ampliamente difundidos como el arroz y el tabaco, condicionando el paisaje no sólo con sus graneros y galpones de apoyo, pero con un modo específico de relación con el territorio. También permanecen testigos de métodos tradicionales constructivos peculiares de las regiones de inmigración, que adaptan materiales nativos con técnicas edificatorias culturalmente heredadas y tejiendo relaciones sociales que no cambian con el tiempo, pero más bien son continuamente adaptadas. Las imágenes que se presentan a continuación quieren traer a la luz, de algún modo, esas características.

Los dos detalles en la Figura 8 son parte de un mapa histórico que está preservado en el Archivo de Tierras del Estado. En él se puede observar, además del esmero gráfico con el uso de diferentes colores, una sorprendente - para la época - precisión geográfica en la ubicación de todos los elementos. Está claro que es una región de contrastes y encuentros: físicamente la extrema organicidad de los elementos geográficos (los ríos y los montes) acaba sobrepuesta por el cartesiano trazado de nuevos caminos y división de glebas. El proceso consistía en medir y demarcar Picadas o Linhas (haciendo referencia al hecho de cortar la mata creando un sendero lo más recto posible) de 5 en $5 \mathrm{~km}$, desde dónde salen, perpendiculares, los lotes coloniales (configurando así, en media, lotes de $200 \mathrm{~m}$ de frente por 2,5km, de largo, un total de aproximadamente 48,5 ha.). Más de cerca se distinguen onomásticos que están totalmente incorporados hoy en día. Están también registrados los nombres de propietarios "originales" y futuros dónde los apellidos y el tamaño del lote denuncia el origen: o portuguesa de tierras tan extensas que siquiera fueron recorridas antes a no ser por pueblos indígenas, o por otro lado inmigrante (alemana en este caso), proporcionalmente mucho más pequeños (siempre conectado en algún punto con cursos de agua).

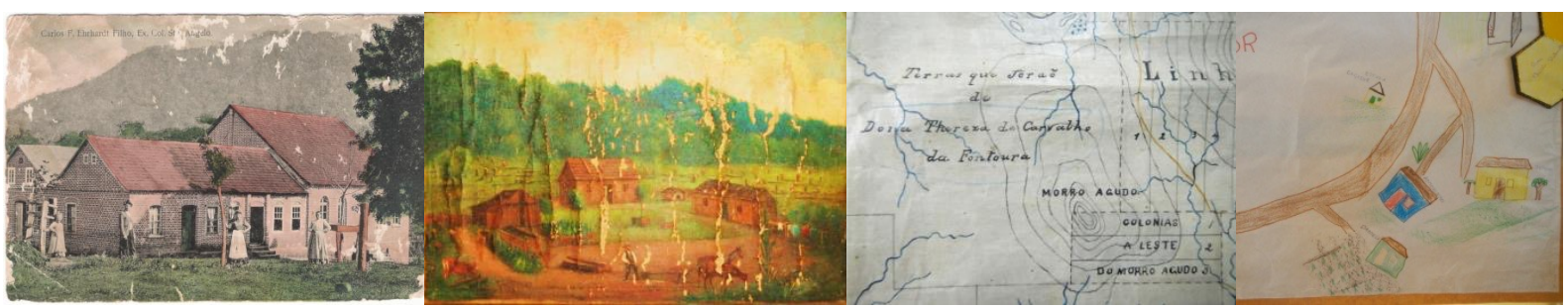

Figura 8. Tarjeta postal de 1901, donde se puede ver el Salón de Baile Ehrhardt. (Archivo personal del propietario del Salón); Al lado, pintura de Alex Puhlmann (1832-1923), medico y pintor de paisajes alemán que vivió en Agudo y región retratando una escena de la vida cotidiana de Agudo. (Archivo del Instituto Cultural Brasileiro Alemão de Agudo); Detalles del primer plan de división parcelaria (Planta da Colônia de Santo Ângelo, terrenos limitrophes-1878), donde se puede notar ya elementos paisajísticos de referencia que hasta hoy son utilizados, como el Morro Agudo. Se puede también observar la relación entre el medio físico y el sistema parcelario de las colonias implantadas. (Arquivo da Divisão de Terras Públicas do Rio Grande do Sul); Detalle de dibujo de escuela primaria sonde son representados caminos de tierra, cultivos, casas y onomásticos del municipio. (Foto del autor, 2013).

Las más diferentes representaciones también son parte definitiva de cómo se mira y se viven los paisajes. En esta tarea están compilados relatos de viajantes, historiadores locales, fotografías antiguas, pinturas, poemas, músicas, etc. En el caso elegido aquí hay unas coincidencias muy importantes entre algunos elementos "representados" y los apuntados en la primera parte de este análisis. El medio "natural" se hace muy presente ya en las fotografías antiguas de familias de principios del siglo XX. Quizá el caso más fuerte sea la Cascada Raddatz que recibe un pequeño altar en el museo del Instituto Cultural Brasileiro-Alemán de Agudo. Sin embargo, la posición del propietario del terreno donde se encuentra el "monumento" es curiosa. Para él "no hay nada especial" en la cascada, por su convivencia perdurable con ella.

Otra recurrencia bellísima es la postal que registra la vivienda y el salón de baile de la familia Ehrhardt, escenario de muchos "kerbs" (fiestas de origen religiosa que duraban dos o tres días debido a las distancias que tenían que ser recurridas, haciendo así que valiera la pena el desplazamiento), 
usuales hasta los años 70 y que hoy en día se concentran en las sedes de los municipios con carácter mucho menos familiar. La pintura arriba adquiere un sentido especial en esta investigación por ser originada por un inmigrante que además de su profesión formal se dedicaba a pintar solamente paisajes. Entre otras cosas demuestra relaciones espaciales muy presentes hasta hoy. Ese simple lienzo pintado al óleo cuenta una historia muy rica y reconocible también en relatos y literatura de época. Desde el duro trabajo de deforestación, debidamente espacializado en la imagen (al fondo del lote), hasta la preparación de la tierra con la ayuda de animales e instrumentos apropiados. También es muy visible una organización del terreno y la disposición de la vivienda así como de los almacenes y galpones de apoyo. Hay otras cosas en esa idealizada pintura que llaman la atención por seguir siendo iguales en los días actuales, además de los aspectos ya subrayados: la estructura de construcción típica de regiones de inmigración de origen alemana en el sur de Brasil, conocida como enxaimel o en idioma original fachwerk (estructuras independientes de madera trabada generalmente rellenada con ladrillos crudos o cocidos, o también con piedras regulares); el instrumento colgado a los bueyes utilizado para revolcar la tierra, como puede ser visto en la foto de abajo, de 2008; los huertos de subsistencia asociados a las viviendas con el detalle de diferentes tipos de plantas aún usuales.

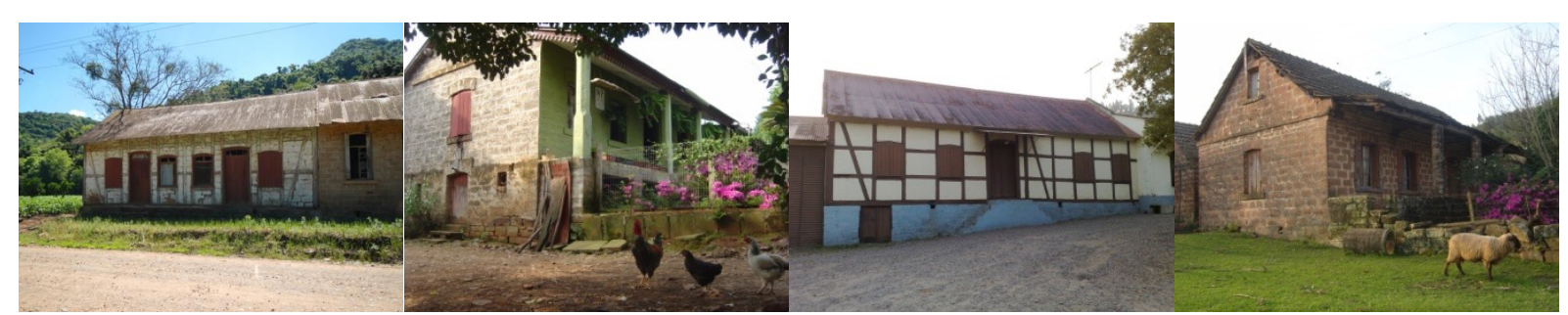

Figura 9. Ejemplares destacados de arquitectura "enxaimel" y métodos tradicionales de construcción presentes en el municipio de Agudo: Salón y casa de comercio Müller - actualmente desactivada, residencia en Linha Boemia, Casa Comercial Müller (Picada do Rio) y residencia en Linha das Flores. Fotos del autor, 2013, 2009, 2010 y 2009 respectivamente.

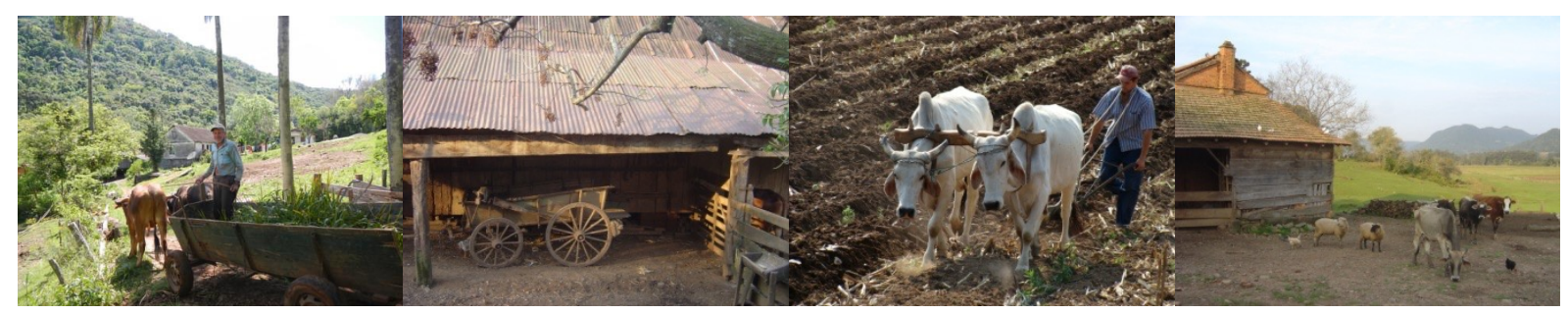

Figura 10. El sr. Oswaldo Raddatz volviendo de una mañana de trabajo en el campo; Instrumentos tradicionales "Carroça"; A la derecha la utilización contemporánea de instrumentos y técnicas de preparo de la tierra como los representados en la pintura anteriormente enseñada del siglo XIX; División, repartición y usos del lote colonial aún recurrentes. Fotos del autor $(2013,2009,2010$ y 2011 respectivamente).

Los registros antiguos históricos también muestran cómo evolucionan urbanísticamente los municipios, desde donde se puede comparar las transformaciones del paisaje, a veces simplemente confirmando lo que aún existe, a veces demostrando cualidades espaciales que fueron perdidas, o bien indicando posibles escenarios futuros. Como se intentó demostrar, en Agudo, la presencia del "entorno natural" o "paisaje" caracterizado por sus propios habitantes es muy fuerte. Un repaso en imágenes antiguas, por ejemplo, puede desvelar algo que apareció en algunas manifestaciones, sobre todo en las asambleas ciudadanas ya mencionadas: el hecho de que hoy haya más vegetación de gran porte y más cobertura vegetal en los montes que en décadas pasadas. De todas formas, la presencia de los montes como fondo ya estaba anotada y celebrada con registros en diferentes momentos de su desarrollo, como confirman las imágenes reproducidas en la Figura 11.

Acercando la escala de análisis en busca de lo cotidianamente perceptible se llega a un modo de visualizar el territorio que los que viven en él hacen sin pragmatismo, pero que es fundamental para su conformación y su aprehensión: desde donde uno mira. Aquí, la investigación parte de recorrer y registrar los principales caminos en búsqueda de elementos peculiares pero también de los repetidos, usuales, que van puntuando y dotando los paisajes de cierta uniformidad pero que a la vez los diferencian de otros. Las coincidencias son considerables teniendo en cuenta los puntos de las encuestas y las interpretaciones más objetivas. 


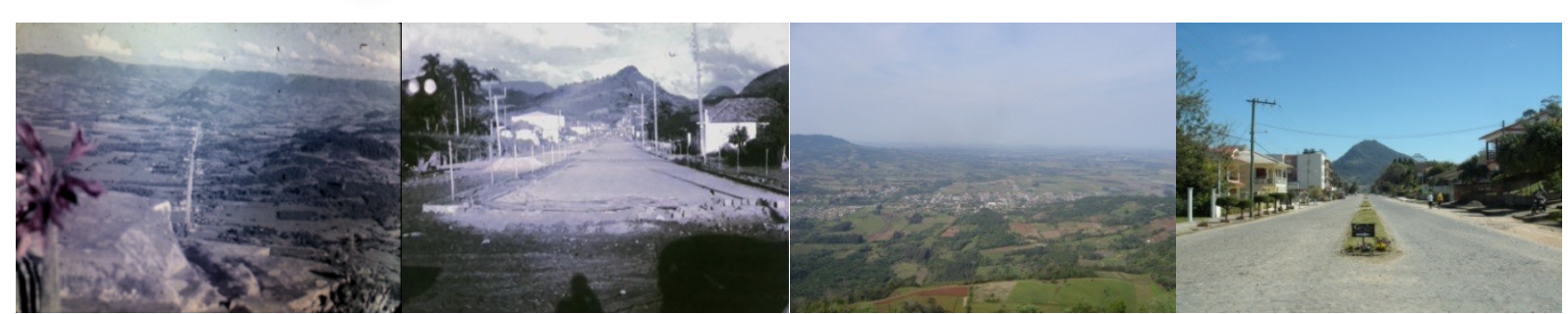

Figura 11. Imágenes de la primera mitad del siglo XX. Vista desde el Morro Agudo hacia la Avenida Concordia, principal calle de Agudo [RS]. Al lado, vista desde la Avenida Concordia hacia en dirección al Morro Agudo. (Ambas del Archivo personal de Erni Böeck); Imágenes actuales de Agudo. Vista desde el Morro da Asa Delta (Finkemberg) hacia la sede del municipio. Al lado, vista desde la Avenida Concordia hacia en dirección al Morro Agudo. Fotos del autor (2008 y 2013 respectivamente).

Por otro lado, también salta a la vista unos elementos dispersos, que en principio pueden ser considerados como 'perdidos', pero que son fundamentales para la apropiación del territorio y que no aparecen para quienes los utilizan continuamente. Si la percepción de la gente en relación al cultivo de arroz (Figura 12) puede llegar a distinguir los diferentes colores que esas grandes áreas sembradas presentan con el paso de las estaciones e incluso sus olores, los sistemas de riego, por ejemplo, no fueron mencionados y componen diferentes tipos de señales, dibujando el territorio de acuerdo con la región que se visita. Los galpones para el secado del tabaco son un elemento de los más vulgares en ese paisaje, a los cuales no se hace referencia; se trata 'simplemente' de construcciones auxiliares. Curioso es que ya se puede incluso notar diferencias tipológicas en esas edificaciones debido a la introducción de especie de tabaco que exige otro tipo de procedimiento más simplificado.

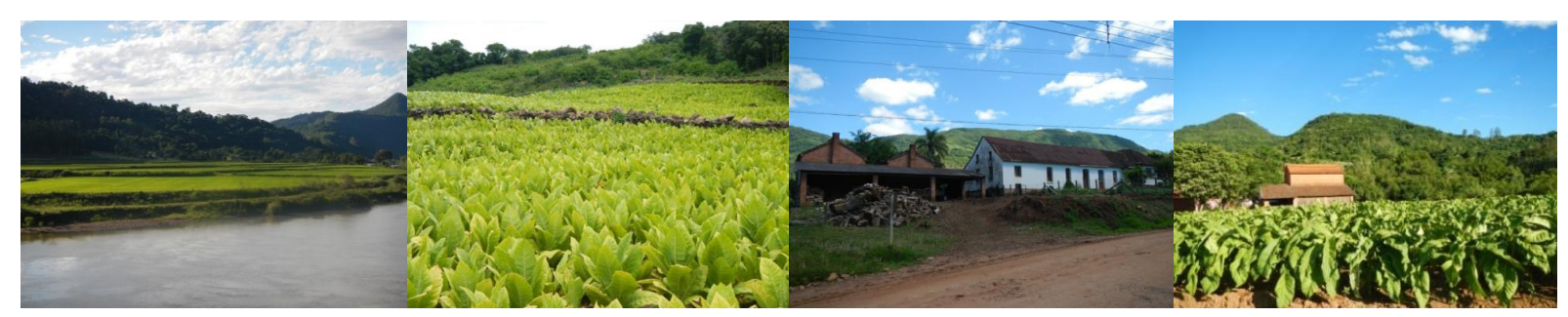

Figura 12. Panorama típico de llanuras cultivadas con arroz con las diferencias de niveles de riego por gravedad y los cerros al fondo; Terrazas y arrimos para el cultivo de tabaco en pendientes. Salón de baile reutilizado como vivienda, galpones maturación del tabaco y los montes característicos al fondo. Fotos del autor (2013).

Además de representar una bella y sensible intervención arquitectónica en el paisaje (Figuras 13 y 14), pueden ser muy característicos en ese nivel de análisis los sistemas de cruce de cursos de agua, especialmente en ese contexto tan rico hidrográficamente. Los puentes colgantes de pasaje peatonal a lo largo del territorio estudiado aunque muy discretos demandan un juicioso trabajo de ingeniería tradicional aquí presente (Figura 14). Muchas veces áreas o puntos de poco interés local tienen un papel fundamental como referencia histórica o mismo estética a contar por su inserción paisajística. Tradicionalmente las familias, esencialmente las luteranas, tenían un lugar particular dentro de la propiedad para enterramientos, y más tarde en cementerios locales, vinculados a la iglesia (Figura 13). Por un lado, son auténticos documentos que guardan nombres de pioneros colonizadores, y por otro pueden ser manifestaciones artísticas que tienen el papel de ilustrar.

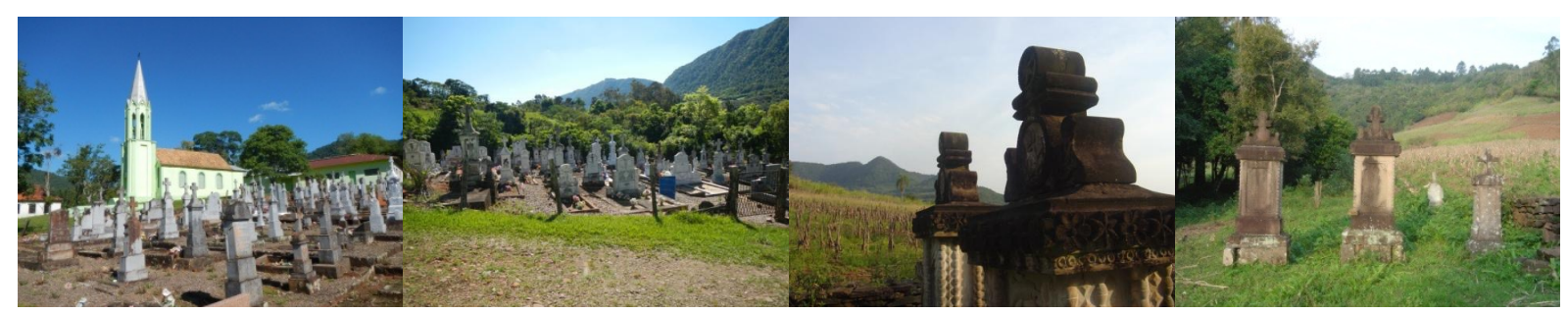

Figura 13. Iglesia Luterana de Linha Boemia y cementerio en el interior de Agudo; Lápidas del cementerio particular de la familia Grellmann (actualmente desactivado). Fotos del autor (2013 y 2008 respectivamente). 


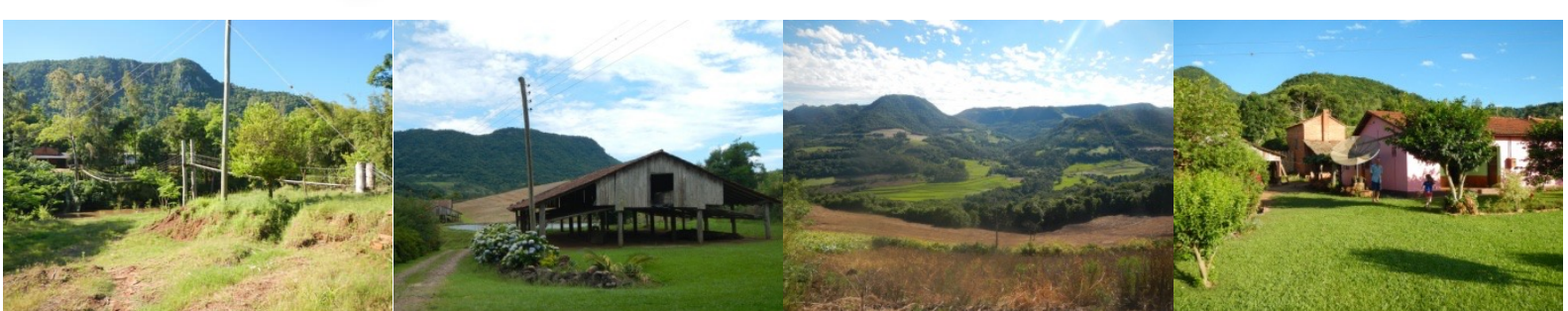

Figura 14. Una pinguela, puente suspendido típico para vencer los cursos de agua más importantes; Galpón de secado de tabaco perfectamente integrado al paisaje; Mescla de cultivos en imagen panorámica del municipio de Agudo; Residencia en Picada do Rio con la mescla de funciones tradicionales, fructíferas y galpón de secado y los llamativos colores de la casa con la antena parabólica en plan principal. Fotos del autor (2013).

\section{Conclusiones}

La serie de análisis presentada busca en su conjunto una lectura del territorio estudiado sumando factores que no siempre son considerados en el contexto local de planificación. El hecho de conocer las percepciones, aspiraciones y relaciones identitarias de la gente con el territorio que lo habita ayuda con que sean contempladas, direccionando procesos de planificación, así como evaluando y jerarquizando valores de uso social. A la vez es un ejercicio que puede ser sistematizado para el autoconocimiento ciudadano, del entendimiento de valores de mayor alcance que los personales en la vida comunitaria.

La incorporación de un análisis histórico-estético, aunque sea también una interpretación parcial, tiene como principal virtud poner en confrontación evaluaciones establecidas que no suelen ser discutidas y tiene como virtud poner luz sobre el patrimonio cotidiano. Es este, según entendemos, que además de proporcionar cualidad de vida, sobrelleva ciertas características de identidad y seguridad, reconocimiento y sentido de pertenencia en relación al territorio. Son valores que, aunque no siempre explicitados por aquellos que los manejan cotidianamente - y justo por eso - deben tener prioridad de tratamiento. Aquí no hablamos solamente de bienes arquitectónicos, pero también formas productivas tradicionales e incluso características subjetivas como el silencio y la amplitud horizontal.

Entendiendo mejor el marco jurídico-institucional que reglamenta - o que puede reglamentar - los paisajes en el Estado, el trabajo busca encajar algunas alternativas o criterios, como los presentados, para que se pueda integrar las visiones del territorio como uso y como recurso que pueden ser manejables con un cierto esfuerzo interinstitucional, y que busquen superar la dicotomía entre natural y cultural. A la falta de un órgano de planificación de escala intermedia específico, la adecuación de nuevos equipos disciplinares, sumado a un cambio epistémico a los órganos de nivel estadual competentes, podría orientar todos aquellos emprendimientos que tengan cierto impacto en el territorio, productivos, energéticos e industriales, compartiendo definiciones y criterios para las áreas no urbanas de Rio Grande do Sul. Aún, podrían, por medio de estudios sistemáticos, definir directrices generales para reglamentación de áreas urbanas como bases para el desarrollo de los Planos Directores, estableciendo así, una jerarquía de planificación en ámbitos que hoy no son posibles.

\section{Referencias}

Berque, A. (1995). Les raisons du paysage - de la Chine antique aux environnements de synthèse. Paris: Editions Hazan.

Bevilacqua, D. et. al. (2009). Plano Ambiental da Quarta Colônia. Santa Maria, RS: UFSM.

D'Angelo, P. (2001). Estética della Natura. Bellezza naturale, paesaggio, arte ambientale. Roma: Editorial Laterza \& Figli.

Mata, R., \& Tarroja, À. (Coords.). (2006). El Paisaje y la gestión del territorio. Criterios paisajísticos en La ordenación del territorio y el urbanismo. Barcelona: Diputació Barcelona. 
Nogué, J. (Ed.) (2008). El paisaje en La cultura contemporánea. Madrid: Editorial Biblioteca Nueva, S.L.

Nogué, J. (Ed.) (2007). La construcción social del paisaje. Madrid: Biblioteca Nueva, Colección Paisaje y Teoría.

Jackson, J. B. (2010). Descubriendo el paisaje autóctono. (Maysi Veuthey, Trad., 1984) Título Original: Discovering the Vernacular Landscape, 1984. In J. Nogué (Ed.) (2010). Paisaje y Teoría. Madrid: Biblioteca Nueva, S. L.

Rio Grande do Sul (2005). Portaria FEPAM no 068/2005.

Rio Grande do Sul (2000). Lei Estadual nº 11.520/2000. Porto Alegre [RS], 2000.

Roger, A. (2009). Breve tratado del paisaje. Edición de Javier Maderuelo. Madrid: Editorial Biblioteca Nueva, S.L.

Sabaté Bel, J. (2008). Paisajes Culturales y Proyecto Territorial. In J. Nogué (Ed.) El paisaje en la cultura contemporánea (pp.249-273). Madrid: Editorial Biblioteca Nueva, S.L.

Sabaté Bel, J., \& Gonzáles, J.G. (2009). El valor estructurante del patrimonio en la transformación del territorio. Apuntes 22(1), 20-33. Bogotá, Colombia.

Schwerz, J. P. (2009). Valores e conflitos na preservação do patrimônio cultural: o olhar técnico e o olhar comum na identificação do patrimônio arquitetônico de Agudo - RS. Dissertação de Mestrado, Universidade Federal de Santa Catarina, Florianópolis, SC, Brasil.

Schwerz, J. P. (2011). Aprehensión del paisaje como patrimonio a partir de la mirada común. Anales de la Convención de Ordenamiento Territorial y Urbanismo - Cultura, Territorio y Ciudad. Habana, Cuba, 14.

Verdum, R. (2012). Perceber e conceber a paisagem. In R. Verdum, L.S. Vieira, B.F. Pinto, \& L. Pires da Silva (Orgs.). Paisagem, leituras, significados, transformações. (pp. 15-22). Porto Alegre, RS: Editora da UFRGS. 